\title{
Sistema ELECTORAL, DESINTEGRACIÓN DE COALICIONES Y DEMOCRACIA EN ChILE: ¿El fin de la Concertación?
}

\author{
Peter Siavelis \\ Department of Political ScIence, Wake Forest University
}

\begin{abstract}
Resumen
Aunque existe bastante desacuerdo respecto a los efectos políticos que tiene el sistema electoral binominal en Chile, muchos concuerdan en que éste proporciona fuertes incentivos para la formación y la permanencia de las coaliciones de gobierno. Este artículo cuestiona estos supuestos, sosteniendo que la capacidad del sistema electoral para inducir la formación de coaliciones depende en la realidad del contexto. Basándose en un análisis de niveles relativos de apoyo electoral entre partidos, la póliza de "recompensa" segura para los perdedores en las elecciones más competitivas, y la sincronización y secuencia de las elecciones presidenciales y legislativas, este artículo delinea las condiciones bajo las cuales el sistema de coaliciones se hace más fuerte o más débil. Concluye que estas variables se alinean para producir un ambiente poco propicio para el mantenimiento de la coalición gobernante con la aproximación de las elecciones presidenciales del 2005. En términos teóricos, el artículo cuestiona las conexiones directas y mecánicas entre sistema electoral y resultados de partido, argumentando que no deberíamos sorprendernos cuando variaciones del entorno causan resultados distintos a los teóricamente esperados. Estos hallazgos contribuyen a un consenso emergente sobre muchas de las reglas teóricas vinculadas a la conexión entre sistema electoral y desarrollo del sistema de partidos basadas en el modelo norteamericano y europeo que, en el peor de los casos es tenue y, a lo más, necesitan ser aplicadas con mucho cuidado en América Latina y en el resto del mundo.
\end{abstract}

\begin{abstract}
While there is much disagreement concerning the political effects of Chile's two-member district binominal election system, most agree that it provides strong incentives for the formation and maintenance of governing coalitions. This article takes on these assumptions, contending that the electoral system's coalition inducing tendencies are actually quite context dependent. Relying on analyses of relative levels of electoral support among parties, a "reward" insurance policy for electoral losers, and the timing and sequencing of elections, this article outlines the conditions under which the coalition-enhancing tendencies of the electoral system are at their strongest and their weakest. It finds that these variables align to provide a less than propitious environment for the maintenance of the Concertación coalition in the lead up to the 2005 elections. In theoretical terms, the article challenges direct and mechanistic connections between electoral formulae and party outcomes, arguing that we should not be surprised when subtle contextual variations cause theorized outcomes not to occur. These findings contribute to an emerging consensus that many of the theorized rules with respect to the connection between electoral and party systems developed on the bases of the US and European models are at worst tenuous, and at best, need to be applied with a good deal of care in Latin America and in other places.
\end{abstract}

\section{PALABRAS CLAVE • Chile • Sistema Electoral • Coalición • Partidos Políticos • Selección de Candidatos}

* Agradezco los comentarios de Evelyne Huber, Jonathan Hartlyn, Greg Weeks, Marcela Rivera y del referí anónimo de Revista de Ciencia Política. 


\section{INTRODUCCIÓN}

Existe una amplia literatura sobre las consecuencias políticas de la reforma electoral en Chile. La mayor parte de ella analiza la continuidad y los cambios que produce el sistema electoral en el número de partidos políticos y en la dinámica de la competencia entre coaliciones (Carey, 2002; Montes et al., 2000; Munck y Bosworth, 1998; Valenzuela y Scully, 1997; Siavelis, 1997). Si bien dentro de la bibliografía que existe al respecto se dan disidencias, la mayor parte de ella coincide en que el sistema electoral estimula fuertemente la formación y conservación de coaliciones, siendo esta formación la llave de la estabilidad del modelo de transición chileno. Ellos sugieren que los efectos sicológicos y mecánicos del sistema electoral siempre aumentan los incentivos para la formación de coaliciones.

Existe una buena cantidad de evidencia que demuestra que los estímulos para la formación de coaliciones han aumentado en comparación al Chile pre-autoritario. Es innegable que la Alianza por Chile ${ }^{1}$ (derecha) y la Concertación (centro izquierda) son las coaliciones más largas y perdurables de la historia contemporánea chilena. Sin embargo, la incuestionable aceptación de los efectos del sistema electoral sobre el fortalecimiento de las coaliciones a menudo se traduce en una tendencia a sugerir que esos incentivos son absolutos e inmutables, y que existen pocas características del sistema que no alientan la formación de coaliciones.

Este artículo cuestiona estos supuestos. Enfocándose principalmente en la formación y el mantenimiento de las coaliciones gobernantes, el trabajo sostiene que la propensión al mantenimiento de las coaliciones del sistema electoral depende bastante del entorno. Se argumenta que los incentivos para formar y mantener coaliciones serán más altos cuando: 1) La selección de candidatos sea facilitada por la relativa paridad en el apoyo de sub-pactos dentro de la coalición; 2) Cuando una posible victoria presidencial posibilite a los gobiernos la capacidad de compensar a los miembros de la coalición que pierden elecciones parlamentarias frente a otros miembros de la coalición; y, 3) Cuando las elecciones presidenciales y legislativas sean simultáneas. Como alternativa, se sugiere que cuando estas condiciones no prevalecen aumentan gravemente las posibilidades que el sistema de coaliciones se socave. Más que los incentivos automáticos que el sistema binominal produce para la formación de coaliciones, las características de las coaliciones del sistema dependen del balance entre los incentivos y desincentivos creados por otras variables del entorno. Desde el retorno de la democracia los incentivos mencionados han tenido, claramente, más peso que los desincentivos señalados más adelante. Sin embargo, este entorno ha cambiado bastante, creando un futuro incierto para la actual coalición gobernante en Chile y la configuración general del sistema de partidos post-autoritario.

Teóricamente, este artículo supone que el análisis de sistemas electorales excesivamente mecanicista predominante en la literatura conlleva a interpretaciones erróneas de la dinámica operacional de formas electorales distintas. Duverger (1963), Taagepera y Shugart (1989), Reed (1990), Lijphart (1994) y Cox (1997) proveen de evidencia convincente y variada sobre la conexión entre los sistemas electorales y los resultados que crean en el sistema de partidos, con importantes repercusiones para los teóricos electorales. Mientras ellos permiten ciertas variacio-

Esta alianza también ha sido conocida en elecciones pasadas como la Unión por Chile, Unión por el Progreso y Democracia y Progreso. 
nes sutiles al analizar distintos casos, en el fondo, mantenemos la visión de la conexión automática entre los efectos del sistema electoral sobre el sistema de partidos. Debemos ser cautelosos al establecer conexiones tan directas y mecánicas, y no sorprendernos cuando repentinas variaciones del entorno causan efectos en el sistema de partidos que no coinciden con lo teorizado. Estos hallazgos contribuyen al nacimiento de un consenso sobre muchas de las reglas teóricas respecto de la conexión entre sistema electoral y desarrollo del sistema de partidos basado en el modelo norteamericano y europeo que, en el peor de los casos, son tenues y, a lo más, necesitan ser aplicadas con mucho cuidado en América Latina y en el resto del mundo (Coppedge, 1997; Weyland, 2002)2.

\section{EL SISTEMA BINOMINAL Y LOS INCENTIVOS PARA LA FORMACIÓN DE COALICIONES}

Las intenciones de transformación que tenían los militares al imponer un nuevo sistema electoral han sido analizadas en extenso (Siavelis, 1997; Valenzuela y Scully, 1997; Munck y Bosworth, 1998, entre muchos otros). En el sistema diseñado, los reformadores pensaron simultáneamente sobre-representar a los partidos de derecha y reducir el número de partidos significativos en el país. Para disminuir el número de partidos, la elección más lógica habría sido un sistema uninominal como el de Estados Unidos o el británico. Sin embargo, los reformistas sabían que con ese sistema la derecha podría confiar sólo en un $40 \%$ de apoyo. Así, con un sistema uninominal, la derecha habría reducido sus escaños en el Congreso. Las autoridades militares optaron, en cambio, por distritos de dos miembros, conocido como "sistema binominal". El sistema se adoptó para cada uno de los 60 distritos de la Cámara (para un total de 120), y para las elecciones del Senado (con 19 circunscripciones para un total de 38$)^{3}$.

La combinación de distritos de magnitudes de dos $(M=2)$ y un sistema de conteo d'hondt crea fuertes umbrales electorales. Cada coalición o partido presenta dos candidatos por distrito. Para obtener ambos escaños la lista que obtuvo el primer lugar debe doblar el total de votos de la lista en segundo lugar. Así, si la lista más votada dobla la votación de la segunda lista, ella obtiene los dos asientos. Si esto no ocurre, cada uno de los más votados de las listas gana un asiento. Después de determinarse si una lista ganó uno o dos asientos, estos son asignados, según la votación propia, a candidatos individuales. El sistema, así, establece umbrales muy altos para la representación. Es muy difícil para una coalición o partido obtener la súper-mayoría necesaria para ganar dos escaños en un distrito (o para "doblarla"). Para las últimas cuatro elecciones democráticas en la Cámara (1989, 1993, 1997 y 2001), la coalición de centro-izquierda, Concertación, consiguió duplicar exitosamente en 11, 11, 9 y 4 veces respectivamente. La Alianza por Chile, coalición de centro-derecha, ha doblado sólo en dos oportunidades durante este periodo, una en 1993, y la otra en el 20014. Así, en la mayoría de los distritos, y dado el patrón bipolar de la competencia, cada coalición esperaba ganar uno de los dos asientos en cada circunscripción (o 60 cada uno), y las peleas más violentas se centraron en los distritos donde una de las coaliciones tenía el potencial para "doblar".

Los hallazgos de Siavelis (1997) sobre los efectos del sistema electoral en el número de partidos son similares.

Hay también nueve senadores designados, no electos.

Dados los resultados electorales que aparecen en la Tabla 1, pareciera que la Concertación dobló en 9, 10, 9 y 3 distritos respectivamente. Sin embargo, el "doblaje" incluye también a quienes no compitieron formalmente en las listas de la Concertación, pero están asociados y apoyados por ella. 
Los militares suponían que distritos de baja magnitud alentarían la fusión de los partidos y que la notoria polarización y fraccionamiento del sistema de partidos chileno serían moderados. Según esta lógica, Chile quedaría, supuestamente, con un sistema bipartidista 0, al menos, con un patrón de competencia entre dos grandes coaliciones. Aunque este argumento se basa claramente en la lógica downisiana respecto de las consecuencias centripetas de distritos uninominales, el argumento de Downs (1957) no se aplica realmente. Primero, dada la teoría electoral sobre sistemas binominales es más probable predecir un sistema de tres partidos que un sistema de dos partidos o coaliciones que se entiende como la norma de los sistemas uninominales (Reed, 1990; Cox, 1997: 159-61). Segundo, distritos de dos miembros producen una dinámica de competencia distinta. Ciertamente, análisis espaciales sugieren que el sistema binominal puede crear dos equilibrios electorales, donde la competencia entre las listas es centrífuga, pero donde los candidatos individuales en la misma lista compiten por el mismo espacio ideológico (Dow, 1998; Magar, Rosenblum y Samuels, 1998).

Joaquín Lavín, un tenaz defensor del sistema binominal (y posterior candidato presidencial), sostiene que este sistema "obliga a la formación de grandes bloques electorales, los cuales moderan sus posiciones y terminan situándose uno cerca del otro" (citado en Enasalaco, 1994: 420). Aunque existe gran desacuerdo en las interpretaciones acerca de los resultados del sistema electoral, la mayoría de los teóricos concuerdan con Lavín en que el sistema proporciona fuertes estímulos para la formación y el mantenimiento de coaliciones, y, ciertamente, establece estímulos mucho más fuertes que los existentes en el pasado (Carey, 2002; Rabkin, 1996; Gutiérrez, 1990: 345-349; Guzmán, 1993; Muck y Bosworth, 1998: 485). Carey lo señala más explícitamente: "La centralidad de las coaliciones en la política chilena en los noventa, además, es un resultado de la reforma del sistema electoral de dos miembros por distrito" (2002:224). Incluso, el autor de este artículo ha subrayado cuanto más fuerte han sido los incentivos para la formación y el mantenimiento de coaliciones desde el retorno de la democracia, así como la naturaleza perdurable de las coaliciones actuales en Chile en comparación con el pasado (2002).

Algunos investigadores admiten tensiones que podrían llevar hacia un final de la Concertación. Pero en vez de reparar en las mismas características del sistema electoral, ellos destacan, casi siempre, la avanzada edad de la Concertación o los conflictos político-sociales - el aborto, la privatización, y el bienestar público - como evidencia del resurgimiento de clivajes que deberían terminar con esta coalición. Ciertamente, los expertos a menudo argumentan que los incentivos para la formación de la coalición proporcionados por el sistema electoral ayudan, de hecho, a desviar estos clivajes y a moderar el conflicto. Lo que plantea este artículo es que hay características institucionales del propio sistema electoral que pueden socavar los incentivos para la formación de coaliciones.

Aunque incentivos similares operan al interior de la Alianza, esta investigación se centra, principalmente, en la Concertación. Muchas de las variables que se exponen aquí tienen el mismo efecto al interior de la Alianza y la Concertación. En particular, la influencia de la igualdad de los sub-pactos y la simultaneidad de elecciones (presidenciales y parlamentarias) podrían ejercer efectos similares en la oposición, siendo incentivos para la formación de coalición. Sin embargo, la capacidad de compensar a los perdedores no se aplica puesto que la oposición (la Alianza) no posee puestos ejecutivos que así lo permitan. La derecha, por otro lado, tiene la fuerza unificadora de una oposición negativa sin tener que acordar en concreto sobre propuestas positivas para gobernar. En la derecha, 
al igual que en la izquierda, la habilidad última para formar y mantener una coalición depende, en general, de la constelación de esas fuerzas. A pesar de esto, dado que la mayoría de los expertos enfatizan en los incentivos electorales para el mantenimiento y la desintegración de la coalición gobernante, este trabajo se limita al análisis de la Concertación. Además, una vez instaurado un gobierno de derecha, como podría suceder pronto, uno podría esperar que operaran en la misma vía estímulos similares para las coaliciones gobernantes, y que las tres variables expuestas aquí sean importantes.

Ahora es el turno del análisis de las variables electorales específicas que sostienen o socavan la unidad en las coaliciones que dirigen Chile.

\section{Sistema binominal, selección de candidatos e igualdad de sub-pactos}

La imparcialidad percibida en los resultados de los procesos de selección de candidatos ha sido central para el mantenimiento de la Concertación. Dada la falta de un partido mayoritario y la continua existencia de un arraigado sistema multipartidista, para competir eficazmente dentro de un sistema caracterizado por umbrales fuertes y pequeñas magnitudes, los partidos deben formar listas pre-electorales para ganar las elecciones. Las dos coaliciones del Chile post-autoritario han realizado estas funciones. Las coaliciones están, en cambio, divididas en dos "sub-pactos", que comparten alguna afinidad ideológica, y forman otra unidad negociadora. La Concertación de centro-izquierda, comprende un sub-pacto de la izquierda (el Partido por la Democracia, PPD; el Partido Socialista, PS) y el centro (Democracia Cristiana, DC; el Partido Radical, PR; y el Social Demócrata $\left.{ }^{5}, \mathrm{SD}\right)$, así como varios partidos más pequeños e independientes asociados con cada sub-pacto. Aunque los nombres de algunos de estos partidos han cambiado, y ha habido uniones y separaciones desde el retorno de la democracia, los centros de apoyo y liderazgo de cada uno han permanecido esencialmente iguales. La Alianza por Chile está compuesta por los dos partidos de derecha más importantes (Renovación Nacional, RN; y la Unión Demócrata Independiente, UDI), cada uno anclado a su propio sub-pacto, centro-derecha y derecha, respectivamente. Estos dos sub-pactos están asociados a pequeños partidos y candidatos independientes. La Figura 1 resume la configuración de estos sub-pactos y coaliciones. 
FIGURA 1: Coaliciones, sub-pactos y partidos en las elecciones parlamentarias chilenas, 1989-2001

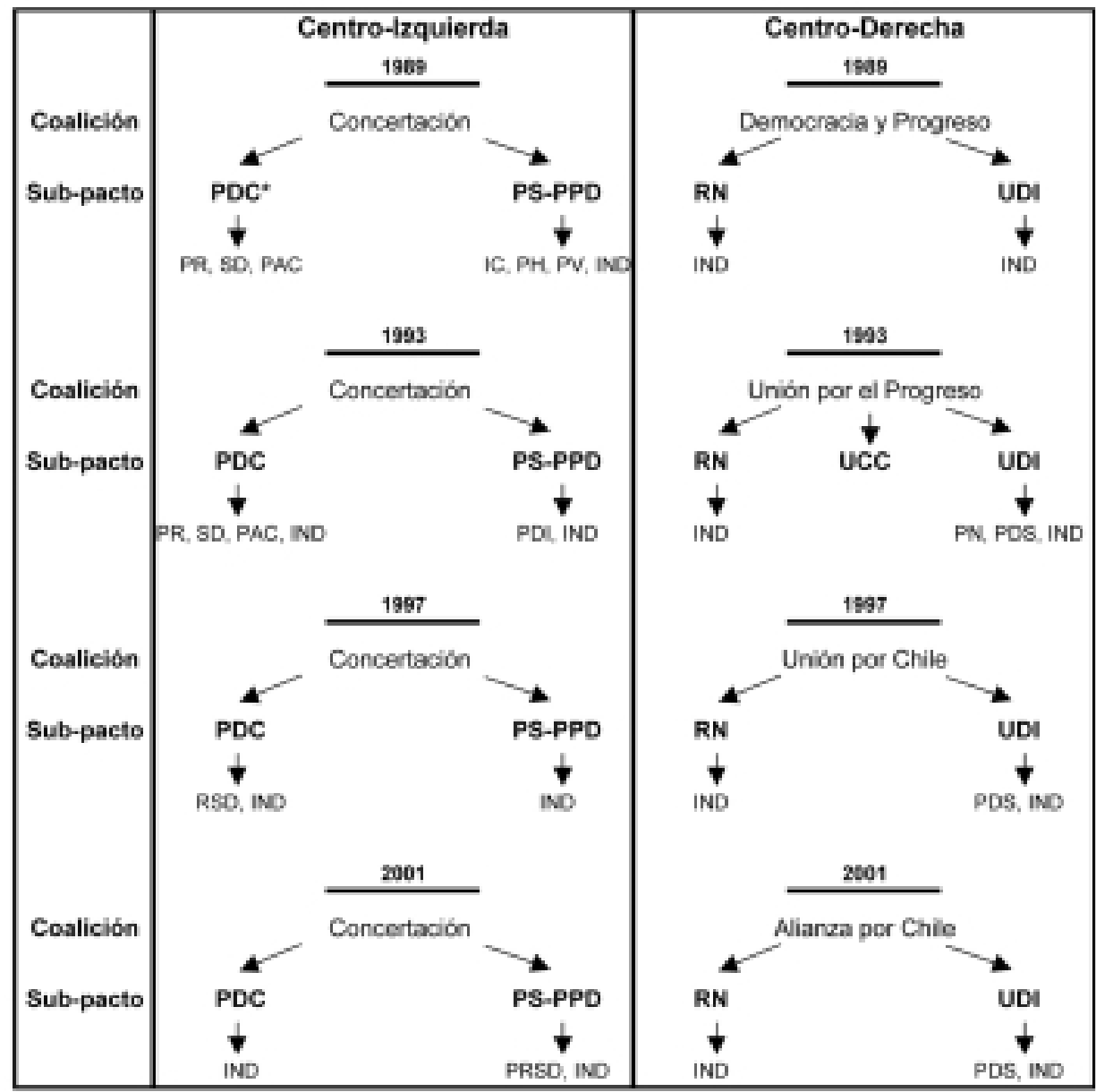

Partidos ancla en negritas.

Abreviaciones: IC-Izquierda Cristiana; IND-Independientes asociados con los sub-pactos; PAC-Partido Alianza de Centro; PDC-Partido Demócrata Cristiano; PDI-Partido Democrático de Izquierda; PH-Partido Humanista; PDS-Partido del Sur; PN-Partido Nacional, PR-Partido Radical; PV-Partido Verde; SD-Social Democracia; RN-Renovación Nacional; RSD-Radical Socialdemócrata, UCC-Unión de Centro Centro; UDI-Unión Democrática Independiente. 
Como cada coalición puede presentar solamente dos candidatos, los líderes de los partidos están forzados a comprometerse en elaboradas y agotadoras negociaciones para reunir listas de dos candidatos en los 60 distritos electorales del país. Que estas negociaciones se hayan realizado con éxito en las últimas cuatro elecciones parlamentarias es una prueba de lo tenaz del sistema de partidos del país y de la habilidad para negociar que tienen los líderes de los partidos chilenos.

Sin embargo, lo mecánico del sistema electoral hace a las negociaciones hoy más cruciales y complejas que en cualquier otro momento del pasado (Siavelis, 2002). Entrevistas con líderes a cargo de la selección de candidatos en cada uno de los partidos más importantes en 1999 y el 2000, y ejemplos empíricos, sugieren una lógica consistente en el proceso de selección de candidatos. Resumidamente, todos los partidos se dan cuenta que para pasar el umbral de un asiento es necesaria, a menudo, una coalición, aunque también saben que es muy difícil para las coaliciones ganar los dos escaños. Así, es probable que uno de los dos candidatos de la coalición pierda en cada distrito.

Esto hace crucial la composición de las listas de candidatos. Los partidos buscan colocar a su candidato en la misma lista con un candidato débil (al que puedan vencer con facilidad) 0 a un candidato muy fuerte (que pueda acarrear a la lista a la victoria de dos asientos). Las negociaciones son aún más complicadas porque los partidos pequeños desean ser colocados no sólo en listas, sino en distritos donde verdaderamente puedan ganar. Es probable que los representantes de los partidos principales derroten a los candidatos de sus socios de partidos pequeños, haciendo que los socios demanden candidatos de lista aun más débiles. Los partidos fuertes no pueden simplemente ignorar las demandas de los partidos pequeños, porque los necesitan para mantener la coalición y asegurar el apoyo de estos en las elecciones presidenciales. Además, muchas posiciones están subordinadas a negociaciones que se dejan para el final. A menudo los partidos están dispuestos a ceder algunos asientos en la Cámara de Diputados a cambio de candidaturas senatoriales. Las diferencias en las metas de los actores generan, principalmente, resultados inesperados y sorprendentes. Mientras las coaliciones procuran maximizar los votos de sus listas, los candidatos no necesariamente están interesados en hacer lo mismo si el maximizar los votos de su lista significa que sus socios sumarán más que ellos. De esta manera surge una competencia mutuamente destructiva al interior de la lista, especialmente si ambos candidatos de la lista compiten codo a codo en los sondeos.

Sin embargo, (y primordial para los argumentos expuestos aquí sobre la disolución de la coalición) entrevistas y evidencia empírica sugieren también que las negociaciones pueden ser más fáciles 0 más difíciles dependiendo de los niveles de apoyo relativo de los sub-pactos. Debido a la existencia de umbrales en el sistema electoral, los partidos ancla de los dos sub-pactos dentro de la Concertación querrán dividir equitativamente las candidaturas cuando conozcan los datos de opinión pública o los resultados de elecciones previas donde gocen de niveles de apoyo relativamente equivalentes a lo largo del país. Cada uno de los partidos ancla puede utilizar esos datos para pelear por más escaños. En situaciones donde los sub-pactos del centro y de la izquierda disfrutan de una relativa paridad, a menudo decidirán dividir equitativamente las asignaciones de los escaños (esto es, tomar una candidatura cualquiera en cada distrito, dividir 60-60) y depositar la confianza en la igualdad de apoyo entre los votantes a través del país, lo que resultará en una victoria balanceada dentro de los dos sub-pactos. 
Por otro lado, cuando los sub-pactos se encuentran a sí mismos con distintos niveles de apoyo, la negociación se hace más compleja y difícil. Si un sub-pacto tiene un nivel de apoyo más bajo que el otro por todo el país, no querrá simplemente dividir los distritos con el sub-pacto más fuerte, porque ello sería una receta para la derrota a lo largo de los distritos. La desigualdad en los niveles de apoyo de los sub-pactos conlleva a dos cosas. Alienta a que el líder del sub-pacto demande más candidaturas e incita al segundo lugar del sub-pacto a ser más cauteloso al acordar un pacto de adhesión de sus candidatos. Sólo a través de arduas negociaciones puede el sub-pacto de segundo lugar ver las colocaciones que le permitirán ganar el asiento. Esto puede hacerse acordando un pacto de omisión donde el sub-pacto más grande concuerde en no llevar candidatos 0 donde acceda en colocar un candidato débil (Siavelis, 2002).

¿Cómo afectarán estas reglas la unidad de la Concertación en el futuro cercano? Por lo pronto, algunas constelaciones de partidos están más propensas al resultado "fácil" en las negociaciones. En esencia, cuando los sub-pactos de la izquierda y centro esperan de los sondeos niveles de apoyo similares, las negociaciones son más simples y hay mayores probabilidades de éxito. Los sub-pactos simplemente dividirán las candidaturas en los distritos. Sin embargo, cuando existe un buen margen de distancia entre los sub-pactos principales, podemos esperar más complicaciones y un menor éxito en las negociaciones, las que estarán caracterizadas por más conflictos intracoalición y una probabilidad más alta de fracaso.

¿Cómo han funcionado estos incentivos en términos empíricos? La igualdad entre los sub-pactos puede ser entendida en términos de votos o de escaños parlamentarios. Los líderes de los subpactos usan ambos grupos de información para negociar y demostrar sus niveles de apoyo. Además, los miembros del Parlamento entienden que tienen el derecho automático de re-nominación, excepto en circunstancias inusuales. Esto significa que la igualdad en los niveles de apoyo en el Parlamento incitará a los líderes a forzar la re-nominación de sus candidatos re-forzando su poder de negociación y su capacidad para colocar a sus candidatos en aquellos lugares donde ya ganaron. La Tabla 1 presenta los resultados para todas las elecciones de diputados desde el retorno de la democracia. Para facilitar el análisis, la Tabla 2 resume la diferencia en el porcentaje de votos y de escaños de los dos mayores sub-pactos de la Concertación. 
TABLA 1: Resultados electorales y distribución de escaños por partido y coalición en la Cámara de Diputados chilena, 1989, 1993, 1997, 2001 (N=120)

\begin{tabular}{|c|c|c|c|c|c|c|c|c|c|c|c|c|c|}
\hline \multicolumn{2}{|c|}{ Año } & \multicolumn{3}{|c|}{1989 (a) } & \multicolumn{3}{|c|}{1993} & \multicolumn{3}{|c|}{1997} & \multicolumn{3}{|c|}{2001} \\
\hline $\begin{array}{l}\frac{0}{u} \\
0 \\
0\end{array}$ & 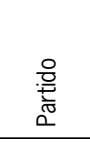 & $\begin{array}{l}\text { बa } \\
\stackrel{0}{0} \\
\stackrel{0}{0} \\
\end{array}$ & 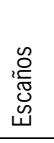 & 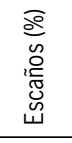 & 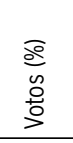 & 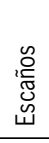 & 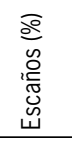 & 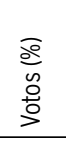 & 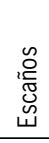 & 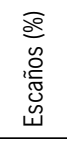 & $\begin{array}{l}\text { बa } \\
\stackrel{0}{0} \\
\stackrel{0}{\circ}\end{array}$ & 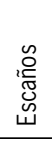 & 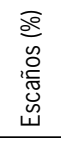 \\
\hline \multicolumn{2}{|c|}{ Concertación } & 51,5 & 69 & 57,5 & 55,3 & 70 & 58,3 & 50,5 & 69 & 57,5 & 47,9 & 62 & 51,7 \\
\hline & PDC & 26,0 & 38 & 31,7 & 27,1 & 37 & 30,8 & 22,9 & 38 & 31,7 & 18,9 & 23 & 19,2 \\
\hline & PRSD(b) & 3,9 & 5 & 4,2 & 3,8 & 2 & 1,7 & 3,1 & 4 & 3,3 & 4,1 & 6 & 5,0 \\
\hline & PS & $0,0^{\text {(c) }}$ & 0 & 0,0 & 11,9 & 15 & 12,5 & 11,1 & 11 & 9,2 & 10,0 & 10 & 8,3 \\
\hline & PPD & 11,5 & 16 & 13,3 & 11,8 & 15 & 12,5 & 12,6 & 16 & 13,3 & 12,7 & 20 & 16,7 \\
\hline & Other & 10,1 & 10 & 8,3 & ,7 & 1 & 8 & 8 & 0 & 0,0 & 2,2 & 3 & 2,5 \\
\hline \multicolumn{2}{|c|}{$\begin{array}{l}\text { Alianza por el } \\
\text { Progreso (d) }\end{array}$} & 34,2 & 48 & 40,0 & 36,7 & 50 & 41,7 & 36,3 & 46 & 38,4 & 44,3 & 57 & 47,5 \\
\hline & RN & 18,3 & 29 & 24,2 & 16,3 & 29 & 24,2 & 16,8 & 23 & 19,2 & 13,8 & 18 & 15,0 \\
\hline & UDI & 9,8 & 11 & 9,2 & 12,1 & 15 & 12,5 & 14,4 & 17 & 14,2 & 25,2 & 31 & 25,8 \\
\hline & Other & 6,1 & 8 & 6,7 & 8,3 & 6 & 5,0 & 5,1 & 6 & 5,0 & 5,3 & 8 & 6,7 \\
\hline \multicolumn{2}{|c|}{ Ind. y Otros } & 14,3 & 3 & 2,5 & 7,9 & 0 & 0 & 13,3 & 5 & 4,2 & 7,8 & 1 & 0,8 \\
\hline
\end{tabular}

Fuentes: Distribución de Asientos: Congreso de Chile. Información Electoral: Servicio Electoral de Chile.

Abreviaciones: PDC-Partido Demócrata Cristiano, PPD-Partido Por La Democracia, PRSD-Partido Radical Social Demócrata, PS-Partido Socialista, RN-Renovación Nacional, UDI-Unión Demócrata Independiente).

(a) Las limitaciones en el registro de partidos impuestas por Pinochet y la fluidez en la identificación partidaria de candidatos, hizo con anterioridad a las elecciones de 1989 difícil la categorización de todos los candidatos. Aunque algunos parlamentarios cambiaron su militancia, la participación en el Partido Socialista fue suprimida más tarde. La identificación partidaria enumerada aquí representa la designación de los candidatos en la elección, y no necesariamente el contingente parlamentario con el cual se asociaron con posterioridad.

(b) Para las elecciones de 1989, 1993, y 1997 estos partidos participaron como el Partido Radical (PR).

(c) Esta cifra es 0 para 1989 a causa de los problemas con la legalización de partidos legales y la cuestión de si el PPD debía disolverse y unirse a los socialistas (una vez legalizados). La mayoría de los votos para los "otros" en la Concertación fueron, de hecho, para los miembros del Partido Socialista.

(d) En elecciones previas este pacto se conoció también como Unión por Chile, Democracia y Progreso y Unión por el Progreso. 
TABLE 2: Diferencias netas (porcentajes) en votos y escaños de los partidos anclas de los subpactos de la Concertación para las elecciones de la Cámara de Diputados, 1989-2001

\begin{tabular}{|c|c|c|c|c|c|c|c|c|}
\hline Elecciones & & 989 & & 993 & & 997 & & 001 \\
\hline $\begin{array}{l}\text { Escaños } \\
\text { Sub-pacto }\end{array}$ & $\% \mathrm{~V}$ & $\% S$ & $\% \mathrm{~V}$ & $\% S$ & $\% \mathrm{~V}$ & $\% S$ & $\% \mathrm{~V}$ & $\% S$ \\
\hline Centro-PDC & 29.9 & 35.9 & 30.9 & 32.5 & 26.0 & 35.0 & 18.9 & 19.2 \\
\hline Izquierda-PS-PPD * & 21.6 & 21.6 & 24.4 & 25.8 & 24.5 & 22.5 & 29.0 & 32.5 \\
\hline $\begin{array}{l}\text { Diferencia neta en Voto / } \\
\text { Asiento Compartido }\end{array}$ & 8.3 & 14.3 & 6.5 & 6.7 & 1.5 & 12.5 & 10.1 & 13.3 \\
\hline
\end{tabular}

Fuente: Tabla 1

* Para todas las elecciones, esto también incluye votos de "otros" sobre las listas de la Concertación. A causa de las limitaciones de registro impuestas por el gobierno de Pinochet, en 1989 la mayor parte de "los otros" en esta lista eran verdaderamente socialistas. Mientras es difícil identificar definitivamente la orientación verdadera de cada candidato, la mayoría se unió al PPD o al Partido Socialista después de la elección de 1989. La diferencia neta en votos es probablemente aun más grande, porque después todos los candidatos mencionados aquí como "otros" no eran miembros de un partido del sub-pacto de izquierda, como se explica en el texto. Para el resto de las elecciones $(1993,1997,2001)$, el autor identificó a todos los candidatos como "otros" en las listas de la Concertación, y fueron miembros del sub-pacto de izquierda, y están contados como tales.

Por las limitaciones sobre encuestas impuestas por el gobierno de Pinochet, en la conducción de las elecciones de 1989 las coaliciones tenían poca información sobre el apoyo relativo que los partidos recién constituidos podían esperar. En un intento por posicionarse mejor, cada partido trabajó para ser el líder en su sector ideológico. Los partidos entendieron lo absurdo de la dinámica de competencia del sistema, comprendiendo que ganar dos asientos era improbable. Sin embargo, corriendo en listas separadas en el centro y en la izquierda habrían entregado la victoria a la derecha y disminuido la probabilidad de un presidente de la Concertación.

Lo urgente de la situación y la meta general de derrotar a candidatos atados al gobierno anterior dirigieron a la Concertación al consenso en que las candidaturas dentro de cada distrito se compartirían igualmente entre los sub-pactos de la izquierda y centro, con algún menor ajuste sobre la base del consentimiento de cada sub-pacto por acomodar a los partidos más pequeños. Existía también un acuerdo tácito entre el sub-pacto PS y PPD con los sub-pactos PDC y PAIS (una lista completamente separada en la izquierda no asociada con la Concertación). La Concertación dividiría uniformemente las candidaturas entre sus dos sub-pactos excepto donde el PAIS sorteaba una lista. En aquellos distritos, dos candidatos del centro serían sorteados evitando la división del apoyo en la izquierda. Además, la lista PAIS acordó apoyar a los candidatos de la Concertación donde aquella no tenía candidatos en competencia. EI PDC, como el partido ancla del sub-pacto, tomó ventaja obteniendo dos asientos en algunos distritos y distribuyéndolos entre sus socios menores. Aun así, el PDC supo que su nivel más alto de apoyo nacional garantizaba la victoria en los distritos donde sus candidatos estaban empatados con los partidos pequeños del sub-pacto.

Sin embargo, los demócratas cristianos sobrepasaron a la izquierda en las primeras elecciones que siguieron al autoritarismo y, en negociaciones iniciadas en las elecciones de 1993, el PDC y sus subpactos lograron ganar un número de candidaturas accionales en el curso de dolorosas y largas nego- 
ciaciones ${ }^{6}$. Como lo muestra la Tabla 2, porque el centro obtuvo 14,3\% más de asientos en la Cámara de Diputados, éste reclamó el liderazgo de la Concertación y presionó fuertemente para la nominación de candidatos de centro. Aunque la tabla muestra una diferencia de $8,3 \%$ en los votos netos entre los dos sub-pactos, la diferencia real es probablemente mayor. Las leyes draconianas en el registro de partido impuestas por Pinochet prevenían la inscripción del Partido Socialista, y muchos identificados como "otros" en la lista de la Concertación para esta elección pertenecieron al PS. No obstante, esta percepción de falta de coherencia debilitó la capacidad de la izquierda para negociar por las listas en las elecciones de 1993, y el centro explotó esto haciendo difíciles las negociaciones.

Aunque en 1993 la izquierda cedió un número de candidaturas al centro, éste logró estrechar la diferencia en los asientos entre la izquierda y el centro del sub-pacto. Como muestra la Tabla 2, la brecha entre los dos sectores cerró con sólo un 6,5\% de diferencia en los votos y un 6,7\% de diferencia en los asientos. Esta creciente paridad en los niveles de apoyo colocó a la izquierda en una posición de negociación más fuerte, alcanzándose para las elecciones de 1997 un acuerdo que, en términos generales, dividiría las candidaturas en cada distrito. Dado el apoyo similar para los dos sectores en las elecciones de 1997 (con sólo 1,5\% de diferencia en el porcentaje de votos), una vez más, la misma dinámica caracterizó las negociaciones para las elecciones de diciembre del 2001 , siendo nuevamente divididas las candidaturas. Aunque hubo un $12,5 \%$ de diferencia en el porcentaje de asientos, la izquierda compitió aun más fuerte que su fuerza electoral (especialmente en lo relacionado con el sub-pacto de centro), lo que no se reflejó en el resultado de los escaños, porque se había privado de una distribución equitativa de las candidaturas codiciadas. Por lo tanto, la izquierda podría reclamar la igualdad con razón, basada en los resultados de las elecciones y demandar que la designación de escaños fuese nuevamente dividida. Con los niveles de apoyo aproximadamente iguales entre los mayores sub-pactos, el sistema binominal crea incentivos electorales menos complejos y asegura negociaciones más fáciles y sinceras (Siavelis, 2002).

Sin embargo, cuando la disparidad entre sub-pactos aumenta, las negociaciones comienzan a ser más arduas y es más fácil que fallen. Como las negociaciones para las elecciones de 1993 demuestran, la desigualdad en los niveles de apoyo entre sub-pactos generó inseguridad en los partidos ubicados en sub-pactos secundarios, quienes sin sacar concesiones del primer subpacto experimentarían derrotas en muchos distritos. Esto también conduce a demandas más altas para candidaturas en partidos que tienen ascenso en los sondeos o éxito en las elecciones. Sin embargo, en 1993 la necesidad agobiante de presentar a un candidato presidencial único, combinado con la concurrencia de elecciones legislativas y presidenciales y la cercanía temporal relativa de la transición democrática, fortaleció los incentivos para que los partidos alcanzaran un acuerdo a pesar de esas tensiones.

Cuando comienzan las negociaciones para las elecciones del 2005, esta lógica sugiere que la negociación será más compleja y divisoria. La Tabla 2 muestra la disparidad más grande en el porcentaje de votos entre los sub-pactos desde el retorno de la democracia y una disparidad en el porcentaje de asientos que es la más alta desde 1989 (sin embargo, esta vez con la izquierda claramente a la cabeza). La discordia potencial en las negociaciones de candidatos que esta desigualdad podría causar, se complicaría por otras áreas de desacuerdo creciente al interior de la Concertación y la fatiga general del público con 12 años de gobierno de una coalición. 
Así, mientras la clave para la unidad de la coalición radica en la capacidad para negociar listas conjuntas, y la necesidad de negociar producida por el sistema electoral, algunos de los incentivos para continuar esta dinámica de negociación disminuirán en el futuro, y probablemente en un futuro cercano. Cuando empiezan las negociaciones para las elecciones parlamentarias del 2005, es probable que la izquierda demande mucho más y que el centro trate de resistir. Además, dadas las dinámicas creadas por el sistema electoral, la izquierda no estará dispuesta a ceder nada en favor del centro en distritos electorales codiciados. Los partidos del centro dirigidos por los demócratas cristianos pueden decidir que ellos tienen más que ganar presentando una tercera lista electoral. Esto permitiría a la DC la presentación de sus candidatos más fuertes en los distritos donde éste es más popular, sin tener que tomar en cuenta las demandas de la izquierda. En este escenario el PDC estaría también en condiciones de colocar en la delantera a su propio candidato presidencial.

Similarmente, y más importante aún, en el curso de las negociaciones el PDC pediría a la izquierda abstenerse de colocar candidatos de izquierda fuertes, o abstenerse completamente de presentar candidatos en ciertos distritos que permitan victorias para el PDC. Sin embargo, la izquierda tendría pocos incentivos para acceder. Como la primera fuerza electoral en la Concertación, la izquierda puede decidir si gana más al presentar una lista electoral separada, así podría colocar a sus candidatos más fuertes donde lo desee. Este es el mejor de los dos escenarios para la izquierda. Su alto nivel de apoyo electoral le permitiría ganar en muchos distritos que de otro modo habrían sido cedidos al centro y, al mismo tiempo, promover más a su propio candidato de izquierda a la presidencia. Así, en el contexto de negociaciones más complejas, y de un nivel más bajo de apoyo para ciertos partidos, la construcción de incentivos del sistema electoral para la coalición decaería significativamente. Al mismo tiempo, y en contraste a 1993, la coalición no podría confiar en la urgencia de una todavía delicada transición democrática o en la necesidad de escoger un solo candidato presidencial como factor adicional de aglutinamiento.

\section{II. "Doblaje" y "el "seguro" político de recompensa como fuente de unidad}

El recurso más importante que tiene la coalición para posesionar a sus partidos constituyentes son las candidaturas parlamentarias. Sin embargo, como se mencionó, existen muy pocos distritos en Chile donde la Concertación o la Alianza pueden aspirar a doblar a su adversario sin una actuación extremadamente fuerte. Aun así, obviamente, la coalición intenta doblar donde es posible, y sus perspectivas para hacerlo dependen de colocar dos candidatos fuertes que puedan proporcionar a la lista los votos necesarios para atravesar el umbral para los dos escaños. También para casos particulares (como todos los distritos en el Senado, y las particularmente visibles carreras por los escaños en Santiago, Valparaíso y Concepción), los partidos procuran colocar a candidatos con un alto nivel de atracción para incrementar la visibilidad y el retorno total de ambos partidos individuales y de la coalición como un todo. Así, las coaliciones encaran la dualidad de procurar colocar a sus mejores candidatos en carreras donde ellos puedan ganar una alta exposición nacional, pero con un riesgo muy alto de derrota si va con otro candidato fuerte cuyo partido tenga metas similares. Obviamente los candidatos más populares prefieren ir en una fórmula de débil/fuerte, porque siendo el candidato fuerte de la lista se tiene la victoria virtualmente garantizada. Sin embargo, la meta colectiva de la coalición funciona contrariamente a la meta política 
individual de candidatos que pretenden la supervivencia política y resisten la fórmula de ir con un candidato fuerte. Cuando compiten con un compañero fuerte, el candidato enfrenta no sólo la competencia contra un muy fuerte candidato de oposición, sino que también compite con un socio fuerte de su propia coalición. En esencia, a menudo la recompensa política para aquellos candidatos más fuertes y visibles es un socio de lista igual de fuerte y visible, jo sea una receta para perder!

El ejemplo más notorio de este caso fue la presentación conjunta del candidato socialista Ricardo Lagos (actual Presidente) con el demócrata cristiano Andrés Zaldívar por el séptimo distrito del Senado (Santiago) en 1989. Indiscutiblemente la figura más importante en la izquierda, Lagos fue víctima del sistema electoral. Lagos obtuvo el $30,6 \%$ de los votos y Zaldívar el $31,3 \%$. Sin embargo, porque el total de sus votos de lista $(61,9 \%)$ no doblaron los votos del total de la lista de la derecha (32,5\%), esta última ganó uno de los dos asientos en este distrito, y Lagos fue derrotado. Esto a pesar que los candidatos de la derecha, Jaime Guzmán y Miguel Otero, obtuvieron el 17,2\% y el $15,3 \%$ de los votos respectivamente.

¿Cómo pueden las coaliciones proporcionar incentivos para que un candidato acepte ir con otro candidato fuerte? Evidencia empírica sugiere que la coalición a menudo proporciona una especie de póliza de "seguro" político en forma de promesas de nominación ministerial u otras posiciones de alto nivel a cambio de las posibilidades de decaer en estas riesgosas elecciones. Los perdedores en comicios altamente competitivos pueden tener cierta seguridad en que sus carreras políticas continuarán a pesar de sus derrotas. El mismo Lagos es un ejemplo de esta dinámica. Inmediatamente después de su derrota fue nombrado Ministro de Educación por el recién instaurado gobierno de Aylwin. Carey y Siavelis (2003) encontraron que no son aislados los casos en que los candidatos fueron premiados después de las elecciones y que, más aún, consiste en un patrón donde el sistema de seguro es usado para recompensar a quienes toman el riesgo. Ellos encontraron que desde el retorno de la democracia, compitiendo en un distrito de alto riesgo (que es donde la Concertación está cerca de doblaje), el derrotado recibía una embajada, un ministerio u otra posición en el Ejecutivo después de las elecciones.

Carey y Siavelis analizan la centralidad del sistema de recompensas para el mantenimiento de la coalición (así como las consecuencias de su desaparición), diciendo poco acerca de las circunstancias bajo las cuales se podría esperar que este sistema de recompensa colapsara. En esencia, hay sólo dos situaciones donde un Presidente puede hacer estas recompensas: 1) Cuando existe un presidente en ejercicio al momento de las elecciones legislativas (como un resultado de elecciones no concurrentes), 0, 2) Cuando hay elecciones simultáneas y la expectación clara de una victoria presidencial. En 1989 Patricio Aylwin tenía virtualmente garantizada la victoria a la luz de los resultados decisivos obtenidos por la Concertación en el plebiscito de 1988. De la mano del enorme éxito que tuvo la presidencia de Aylwin, el demócrata cristiano Eduardo Frei fue elegido como el abanderado único de la Concertación y fue un líder temprano y categórico en los sondeos anteriores a la formación de la lista legislativa. El periodo de seis años del Presidente Frei significó que las elecciones legislativas de 1997 tuvieran lugar cuando todavía le quedaban dos años de su periodo, tiempo suficiente para proporcionar nominaciones de cargos como compensación a los perdedores de estos distritos competitivos. Finalmente, las elecciones legislativas más recientes, ocurridas en el 2001 y a cuatro años de finalizar el periodo del Presidente Lagos, implicaron la disponibilidad de más nominaciones compensatorias. A pesar de la estrecha victoria de Lagos en 
la segunda vuelta electoral, su triunfo había sido ampliamente predicho por los analistas políticos. En cada uno de estos ejemplos, la victoria asegurada permitió a la Concertación proporcionar un "seguro" a los candidatos de alto riesgo y garantizarles que no se irían sin recompensas por su dedicación a la coalición.

La situación política contemporánea en Chile es distinta a cualquier otra época desde que comenzó la transición democrática. El impacto que Lavín causó en las elecciones de 1999 ha derivado en pronósticos acerca de la derrota de la Concertación. Así, no existe certeza de una victoria electoral que pudiera producir las recompensas necesarias para los candidatos que asumen un alto riesgo en las negociaciones lideradas para las elecciones del 2005. En las condiciones actuales sería bastante difícil para la Concertación hacer cualquier promesa creíble de nominación de cargos en el Ejecutivo después de la elección.

Mientras esto parezca sólo un punto secundario, aplicable a unos pocos distritos de alta visibilidad, esta dinámica general también operará como un todo al nivel de la coalición. Sin la fuerza unificadora de una esperada victoria en la elección presidencial, y en medio de la declinación de la popularidad del centro, la izquierda puede decidir que éste es su mejor interés para evitar negociaciones sobre el candidato de la lista y colocar a sus candidatos más fuertes donde pueda confiar en el apoyo de sus partidarios. Este es el caso, por cierto, porque con un número diferente de listas los cambios de la dinámica competitiva del sistema binominal cambian y los umbrales disminuyen. La izquierda puede decidir si efectivamente puede sobrepasar al PDC en más distritos con sus propios dos miembros de lista. En este caso, la izquierda necesita sólo ganar a los demócrata cristianos y a sus aliados para aproximarse a la victoria de un asiento en cada distrito (asumiendo que la derecha también obtiene uno). Efectivamente, el resultado sería incluso más beneficioso para la izquierda, porque ésta tendría la completa libertad para colocar a sus mejores candidatos en los distritos donde tienen más oportunidades de ganar sin tener que hacer concesiones al centro.

\section{Elecciones simultáneas y mantenimiento de la coalición}

Los cientistas políticos han subrayado la importancia de la sincronización y la secuencia de las elecciones en el delineamiento de los resultados electorales (Jones, 1995; Shugart, 1995; Mainwaring y Shugart, 1997; Carey, 1994). Se ha dicho que las elecciones simultáneas reducen la fragmentación del sistema de partidos y fortalecen la probabilidad de que los Presidentes obtengan mayorías legislativas. En esencia, estos aspectos de las elecciones simultáneas pueden facilitar la operación de la a veces comprometedora combinación de presidencialismo y representación proporcional (PR), dada la mayor seguridad en que el Ejecutivo podría confiar en mayorías y trabajar con una pluralidad de sus propios partidos. Inversamente, otros analistas sostienen que sin elecciones simultáneas los Presidentes quedan a menudo sin mayoría o con mayorías sobre las cuales ellos no pueden confiar, incrementándose la fragmentación de partidos y tendiendo a emerger los inherentes desincentivos a la cooperación que produce el presidencialismo (ver Linz, 1994; Valenzuela, 1994). En Chile, el Ejecutivo sirve por un periodo de seis años, los miembros de la Cámara de Diputados son elegidos cada cuatro años, y los senadores son electos por ocho.

Aunque el período para los senadores es ocho años, la mitad del Senado se renueva cada cuatro. Esta sincronización puede privar a un presidente de una mayoría en la Cámara Alta, a pesar de una victoria abrumadora para su partido en las elecciones senatoriales. 
Entre estas elecciones (no necesariamente simultáneamente) están las elecciones municipales cada cuatro años. Así, Chile realmente tiene un diseño electoral sub-óptimo con relación a la sincronización y la secuencia de las elecciones. La Tabla 3 resume este calendario electoral.

TABLA 3: Sincronización y secuencia de las elecciones en Chile, 1989-2011

\begin{tabular}{|c|c|c|c|}
\hline & Presidenciales* & Legislativas & Municipales \\
\hline 1989 & X (Aylwin) & $x$ & \\
\hline \multicolumn{4}{|l|}{1990} \\
\hline \multicolumn{4}{|l|}{1991} \\
\hline 1992 & & & $x$ \\
\hline 1993 & $X$ (Frei) & $x$ & \\
\hline \multicolumn{4}{|l|}{1994} \\
\hline \multicolumn{4}{|l|}{1995} \\
\hline 1996 & & & $x$ \\
\hline 1997 & & $x$ & \\
\hline \multicolumn{4}{|l|}{1998} \\
\hline 1999 & X (Lagos) & & \\
\hline 2000 & & & $x$ \\
\hline 2001 & & $x$ & \\
\hline \multicolumn{4}{|l|}{2002} \\
\hline \multicolumn{4}{|l|}{2003} \\
\hline 2004 & & & $x$ \\
\hline 2005 & $x$ & $x$ & \\
\hline \multicolumn{4}{|l|}{2006} \\
\hline \multicolumn{4}{|l|}{2007} \\
\hline 2008 & & & $x$ \\
\hline 2009 & & $x$ & \\
\hline \multicolumn{4}{|l|}{2010} \\
\hline 2011 & $x$ & & \\
\hline
\end{tabular}

* Aunque Aylwin tuvo un gobierno de transición de cuatro años, el periodo presidencial es ahora de seis.

Incluso con todos los problemas de la sincronización y secuencia, los investigadores del caso chileno reconocen que la conexión entre las elecciones legislativas y presidenciales crea fuertes incentivos para la formación de coaliciones (Siavelis, 2002). El sistema electoral binominal aumenta la apuesta por un candidato presidencial único $\mathrm{y}$, a su vez, refuerza los incentivos para la creación y el mantenimiento de listas electorales compartidas en las elecciones del Congreso. El fracaso en el acuerdo de un candidato presidencial único puede ocasionar el fraccionamiento de las alianzas para la competencia legislativa. No alcanzar los umbrales establecidos por el sistema binominal es extremadamente costoso para un partido, y puede desembocar en su exclusión del Congreso. Los partidos corren un alto riesgo si fallan al unirse detrás de un abanderado para las elecciones presidenciales, los cuales, en cambio, menoscaban su potencial de éxito en las elecciones legislativas. Así, la naturaleza del presidencialismo chileno eleva el costo de la falla en las 
negociaciones y, de nuevo para los que apoyan el sistema binominal, provee fuertes incentivos para la formación y el mantenimiento de coaliciones.

La durabilidad de la Concertación certifica el fuerte poder aglutinador del sistema electoral. Los demócratas cristianos estuvieron de acuerdo en apoyar la candidatura altamente riesgosa del socialista Ricardo Lagos en 1999. La minúscula mayoría relativa de Lagos en la primera vuelta de la elección demostró a la DC cómo un candidato presidencial socialista puede erosionar los votos del lado derecho de la Concertación. Sin embargo, la Concertación insistió en sostener un candidato único, dada la cercanía de las elecciones parlamentarias y el costo que tendría para la alianza en su conjunto el que la Concertación se dividiera en dos listas separadas para las presidenciales y las parlamentarias.

Sin embargo, los incentivos fortalecedores de la coalición generados por la sincronización y secuencia de las elecciones pueden operar de una forma diferente a la luz del análisis presentado aquí. En primer lugar, cuando las elecciones presidenciales y legislativas no son simultáneas, es probable que la formación de coalición se complique, porque el proceso de selección de candidatos será comprobadamente más difícil. Como se señaló, si el mayor de los sub-pactos no es igualado apenas en apoyo, es probable que las negociaciones sean más conflictivas. En 1993 existía bastante disparidad en los niveles de apoyo de los sub-pactos del centro y la izquierda, y como se refleja, los centristas del PDC fueron capaces de extraer un alto número de candidaturas en las negociaciones. Sin embargo, es crucial recordar que hubo una elección presidencial simultánea en 1993. Las elecciones simultáneas facilitaron las negociaciones reduciendo el potencial número exagerado de asientos que el PDC podría haber demandado dada su ventaja electoral y en el número limitado de asientos que la izquierda habría fallado en entregar para asegurar ser parte de la coalición presidencial ganadora. Sin elecciones simultáneas algunos de los desincentivos para la unidad de la coalición, que necesariamente surgen cuando los sub-pactos no disfrutan de niveles similares de apoyo, habrían sido, certeramente, mucho más fuertes. De igual forma, porque los dos sub-pactos de la Concertación estaban relativamente iguales en apoyo en dirección a las elecciones de 1997 y del 2001, la negociación por las candidaturas fue menos compleja y la necesidad de unificación de la candidatura presidencial urgía menos. Sin embargo, el punto es que la urgencia y los beneficios de una lista cohesionada son probablemente mucho más altos en un contexto de una elección simultánea, especialmente cuando se espera que el candidato presidencial gane.

Segundo, aun en el contexto de elecciones simultáneas, cuando la victoria presidencial es incierta, los incentivos para el mantenimiento de la coalición vinculados a las pólizas de "seguro" político son mucho menos probables de desarrollar. La sombra de una elección presidencial inminente puede ser insuficiente para generar incentivos para que los candidatos acuerden ir juntos como socios de coalición porque al ser derrotados, no esperarán recompensas por su dedicación a la coalición.

Tercero, en el contexto de elecciones simultáneas, los incentivos para la formación y el mantenimiento de la coalición realmente dependen de si es o no una coalición que mantiene la presidencia o la mayoría legislativa. En elecciones no-simultáneas, cuando la coalición enfrenta una elección legislativa, pero mantiene la presidencia, incentivos moderadamente positivos a cooperar todavía existen, porque los partidos pueden ser reacios a la disolución de una coalición de gobierno. Existirá, incluso, un similar incentivo moderadamente positivo para el mantenimiento de la coalición en elecciones no simultáneas donde una coalición enfrente una elección presidencial, pero quiera mantener una mayoría legislativa. 
Finalmente, y por cierto, menores incentivos para el mantenimiento de la coalición existirán en elecciones no simultáneas donde los candidatos presidenciales no se beneficien de una mayoría legislativa, o donde ocurran elecciones simultáneas, pero se espera que pierda el Presidente.

\section{PARIDAD, VICTORIA PRESIDENCIAL Y ELECCIONES SIMULTÁNEAS: UN RESUMEN DE LOS INCENTIVOS PARA LA DISOLUCIÓN DE LA COALICIÓN}

Los analistas han notado correctamente que el sistema binominal proporciona algunos incentivos fuertes para la construcción y el mantenimiento de la coalición. Sin embargo, a menudo se inclinan por aglomerar a todas las características operacionales del sistema conjuntamente, ignorando importantes variaciones contexto-dependientes. El sistema no ha estado vigente por un tiempo suficiente como para ver su influencia completa en la dinámica de formación de las coaliciones gobernantes.

La Tabla 4 resume las tres variables significativas que este artículo ha argumentado pueden afectar negativamente los incentivos para la formación de coaliciones: la influencia de la paridad del sub-pacto, la capacidad del gobierno para recompensar el alto riesgo electoral de los perdedores (la póliza de "seguro" político), y la influencia de la sincronización de elecciones.

TABLA 4: Mapa de incentivos para la formación de coaliciones en las elecciones parlamentarias chilenas

\begin{tabular}{|c|c|c|c|c|c|}
\hline Año & 1989 & 1993 & 1997 & 2001 & 2005 \\
\hline Tipo de Elección & $P / L$ & $P / L$ & L & L & $\mathrm{P} / \mathrm{L}$ \\
\hline $\begin{array}{l}\text { Influencia de } \\
\text { la Paridad de } \\
\text { Sub-Pactos (1) }\end{array}$ & Positivat & $\begin{array}{l}\text { Moderadamente } \\
\text { Positiva }\end{array}$ & Positiva & $\begin{array}{l}\text { Moderadamente } \\
\text { Positiva }\end{array}$ & Negativa \\
\hline $\begin{array}{l}\text { Capacidad del } \\
\text { Gobierno para } \\
\text { recompensar a } \\
\text { los perdedores }\end{array}$ & Positiva & Positiva & $\begin{array}{l}\text { Moderadamente } \\
\text { Positiva }\end{array}$ & $\begin{array}{l}\text { Moderadamente } \\
\text { Positiva }\end{array}$ & Negativa \\
\hline $\begin{array}{l}\text { Influencia de } \\
\text { Elecciones } \\
\text { Simultáneas (3) }\end{array}$ & Positiva & Positiva & $\begin{array}{l}\text { Moderadamente } \\
\text { Positiva }\end{array}$ & $\begin{array}{l}\text { Moderadamente } \\
\text { Positiva }\end{array}$ & $\begin{array}{l}\text { Moderadamente } \\
\text { Positiva }\end{array}$ \\
\hline
\end{tabular}

* $\quad$ P=Presidenciales, L=Legislativas, † Dado que no habían elecciones "previas" y faltaba información sobre la opinión pública, esto es considerado positivo, como se explica en el texto.

(1) Influencia de la Paridad de Sub-pactos: Positiva: negociaciones "fáciles", menos que el 10\% de diferencia tanto en el porcentaje de votos como asientos. Moderadamente Positiva: dificultad "intermedia" en las negociaciones, más que el $10 \%$ de diferencia en el porcentaje de votos o asientos entre sub-pactos en elecciones previas. Negativa: negociaciones "difíciles", más que el 10\% de diferencia tanto en votos como asientos entre sub-pactos en elecciones previas.

(2) Capacidad del Gobierno para recompensar a los "perdedores" (la póliza de "seguro"): Positiva: Una segura victoria de la coalición en elecciones simultáneas. Moderadamente Positiva: elecciones legislativas no simultáneas con un presidente de la coalición en el poder. Negativa: victoria incierta o expectativas de derrota en elecciones presidenciales simultáneas.

(3) Influencia de Elecciones simultáneas. Positiva: elección presidencial y legislativa simultánea con expectativas de un ganador presidencial. Moderadamente Positiva: elección simultánea con expectativas de derrota presidencial 0 elección legislativa no simultánea con un presidente en ejercicio. Negativa: elecciones no simultáneas con expectativas de derrota presidencial. 
Hay varias advertencias al respecto. Primero, el modelo no sugiere que éstas son las únicas variables que impactan sobre la formación y el mantenimiento de la coalición. La tabla se centra, más bien, en los descuidados efectos negativos del sistema electoral sobre los incentivos de formación de coalición que pueden agravar o mitigar los conflictos políticos más evidentes. Segundo, debe notarse que las tres variables interactúan en una manera compleja, y que aquí sólo con propósitos analíticos se sitúan aparte.

En términos de la paridad del sub-pacto, este artículo ha argumentado que ésta facilita las negociaciones. Evidencia empírica y el modelo de selección de candidatos sugieren que cuando los partidos de un sub-pacto son casi equivalentes en el nivel de apoyo nacional, las negociaciones para las listas electorales se simplifican y contribuyen, en cambio, mejor a la unidad de la coalición. Esas negociaciones de listas de candidatos para las elecciones siguientes suelen apoyarse en resultados electorales previos y en el tamaño del contingente parlamentario para presionar sobre sus socios y, así, obtener más escaños. Cuando existe paridad, las negociaciones se simplificarán y los partidos estarán más deseosos de simplemente dividir las listas entre los principales sub-pactos, porque el riesgo de las negociaciones será mucho menor, ya que cada sub-pacto esperará ganar apenas el mismo número de asientos a lo largo del país. La Tabla 4 clasifica la influencia de la paridad de sub-pacto como positiva donde hay menos de $10 \%$ de disparidad en el porcentaje de votos y asientos entre los sub-pactos en elecciones anteriores. La influencia de estas variables está clasificada como una ventaja moderada para la formación de la coalición donde hay menos de un $10 \%$ de diferencia entre los votos o asientos de los dos sub-pactos en elecciones anteriores. La desigualdad sub-pacto tendría una influencia negativa cuando hay más de un $10 \%$ de diferencia, tanto en el nivel de votos y asientos de los dos mayores sub-pactos. La cifra del $10 \%$ es, ciertamente, arbitraria. Además, ésta sólo toma en cuenta cambios en el apoyo partidario en la Cámara Baja dado el menos dramático cambio que ocurre en el Senado, porque sólo una mitad de la Cámara Alta es renovada en cada elección. El punto es que cuando hay diferencias significativas en el nivel de apoyo demostrado para los sub-pactos, en términos de asientos o votos (o cambios dramáticos, como la bajada espectacular en el nivel de apoyo para los demócrata cristianos en el 2001), la dinámica de las negociaciones se complicará y disminuirá la probabilidad de éxito.

En términos de la capacidad del gobierno para premiar a los perdedores, el modelo sugiere que una victoria presidencial esperada aseguraría a los perdedores la recompensa. Alternativamente, una victoria incierta para un presidente 0 una esperada derrota proporciona un incentivo negativo para el mantenimiento de la coalición. Por supuesto cuando las elecciones legislativas ocurren en mitad del periodo presidencial, los Presidentes tendrán menos oportunidad de proveer recompensas concretas para los candidatos de alto riesgo, porque en esta situación no hay una renovación completa de puestos públicos y hay menos disponibilidad para premiar a los perdedores Sin embargo, los presidentes tienen la capacidad para proporcionar un número limitado de recompensas, por lo que esta situación proveerá un efecto de reforzamiento moderadamente positivo para el mantenimiento de la coalición. En situaciones donde hay sólo una elección presidencial, los nuevos Presidentes tienen más flexibilidad para recompensar a los perdedores en las elecciones anteriores, ejerciendo una positiva influencia para el mantenimiento de la coalición. 
Finalmente, con respecto a las elecciones simultáneas, una elección presidencial y legislativa simultánea con una victoria presidencial segura proporcionaría el más fuerte apego de la coalición. Paralelamente, elecciones no simultáneas con expectativas de pérdida en la elección presidencial ocasionarían un desincentivo en el mantenimiento de la coalición. Una elección simultánea sin un ganador presidencial esperado provocaría una ventaja moderadamente positiva para el mantenimiento de la coalición dado que, incluso con un perdedor, un candidato presidencial común proporcionaría un reforzamiento de la unidad para las elecciones legislativas, donde los candidatos aún necesitarían acumular suficientes votos para cruzar los umbrales cruciales. Como la Tabla 4 lo indica, aún las elecciones no simultáneas pueden proporcionar una influencia moderadamente positiva sobre la unidad de coalición. Esto ocurre en elecciones donde una coalición mantiene la presidencia (en el caso de las elecciones legislativas) o una mayoría en la legislatura (en el caso de elecciones presidenciales). Esto ocurre simplemente porque los políticos tienen un incentivo para mantener una coalición exitosa y apostar hacia el triunfo en cualquier tipo de elección futura.

La evidencia empírica de elecciones pasadas apoya las clasificaciones resumidas en la Tabla 4. De acuerdo a los intereses de unidad de coalición y estabilidad de la transición democrática, en las elecciones de 1989 los partidos de la izquierda acordaron apoyar al demócrata cristiano Patricio Aylwin. Aunque no hubo paridad en los niveles de apoyo de los dos sub-pactos, existió una gran incertidumbre, la cual produjo la presunción general de igualdad probada. La victoria en la carrera presidencial estaba asegurada, junto con la expectativa de un presidente con la capacidad de recompensar perdedores en el contexto de elecciones concurrentes. La unidad de la coalición durante este periodo fue algo sin precedentes.

En 1993, los sub-pactos de la Concertación no se beneficiaron de la paridad relativa (volver a la Tabla 2). Las elecciones de 1989 habían proporcionado al centro (PDC-PRSD) el 29,9\% de los votos, mientras los partidos de la izquierda recibieron el 21,6\% (sin embargo, esta cifra incluyó muchos "otros" en la elección, quienes, como se mostró, no fueron considerados miembros del sub-pacto de izquierda por el partido demócrata cristiano). Esto colocó a la izquierda dentro de una posición débil en preparación para las elecciones de 1993, e hizo las negociaciones de candidatos más mordaces y complicadas (Siavelis, 2002). Aunque la Tabla 4 clasifica estos resultados como condiciones negociadoras "moderadamente positivas" para las elecciones de 1993 (porque la variación en los votos entre los sub-pactos es menor al 10\%), uno podría hacer un argumento creíble que debiera estar caracterizado como negativo dada la percepción de falta de coherencia de la izquierda en la primera elección, la que minimizó el sentimiento de su poder electoral en los votantes. A pesar de esto, la certeza de la victoria presidencial condujo a una amplia cooperación, la cual se acentuó por las elecciones simultáneas permitiendo funcionar los otros incentivos para la formación y el mantenimiento de coaliciones aquí analizados.

En 1997, la relativa paridad en los niveles de apoyo de los sub-pactos de la coalición (como se evidenció en los resultados de las elecciones de 1993) facilitó las negociaciones para las listas parlamentarias. El voto de la izquierda aumentó al $24,4 \%$ versus el 30,9\% del centro. También, el relativo estrechamiento en la distribución de los asientos entre las dos sub-pactos (a pesar de la desventajosa posición en que quedo la izquierda en la distribución de candidaturas antes de las elecciones de 1993) facilitó la igualdad, proporcionó más poder negociador a la izquierda y resultó en la simple decisión de dividir las listas de candidatos para las elecciones de 1997, ayudando a la 
cooperación. Mientras no hubo elección presidencial para permitir la distribución inmediata de puestos en el Ejecutivo, el gobierno de turno estuvo en posición para hacer promesas a los candidatos perdedores de las elecciones legislativas, produciendo una capacidad moderadamente positiva para recompensar a los perdedores. El efecto de la elección simultánea fue también moderadamente positivo, dado que la coalición duradera pudo beneficiarse de un presidente en ejercicio. Además, la sombra de las elecciones presidenciales de 1999 y la victoria segura de Lagos (entonces presumida) también ayudaron para ejercer un efecto positivo en el mantenimiento de la coalición.

Finalmente, en el 2001 continuó la equidad de los sub-pactos facilitando un acuerdo sobre las listas parlamentarias. Los resultados de las elecciones legislativas de 1997 situaron al pacto PDCPRSD en el $26,0 \%$ y a la izquierda combinada en el $24,5 \%$, con sólo un $1,5 \%$ de margen de diferencia. A pesar de esto, una disparidad de un $12,5 \%$ en el porcentaje de asientos hizo las condiciones de la negociación moderadamente positivas. El gobierno tuvo la capacidad para recompensar a los perdedores (con un Presidente en ejercicio y elecciones legislativas), y la coalición pudo confiar en una coalición fuerte en la Presidencia para suavizar los otros efectos negativos de elecciones no simultáneas, lo que implicó que las elecciones simultáneas produjeran una influencia moderadamente positiva.

La gran pregunta es, ¿qué pasará en el 2005? ¿Seguirá existiendo la Concertación? La Tabla 2 muestra que con la aproximación de las elecciones del 2005 la coalición no podrá depender de la paridad entre los sub-pactos de la coalición. El apoyo para los demócratas cristianos ha decaído y su posición como el partido más influyente dentro de la Concertación ha cambiado, con el subpacto de la izquierda substituyendo al sub-pacto del PDC como líder de la alianza. Regresando a las elecciones del 2001 dado el sólo 18,9\% del PDC en contraste con el 29,0\% de la izquierda en términos de votos populares ${ }^{8}$. La izquierda logró una cuota de 39 asientos, versus 23 del PDC, produciendo un disparidad de $13,3 \%$ en el porcentaje de asientos. Ésta es la disparidad de escaños más grande que ha existido entre los dos sub-pactos desde las elecciones de 1989 y la más grande en términos de votos desde el retorno de la democracia.

Según muchos analistas (y algunos sondeos) una potencial victoria presidencial para la Concertación es incierta dado el éxito del candidato de la UDI Joaquín Lavín en las últimas elecciones y los signos de debilidad presentados en la Concertación ${ }^{9}$. Sin embargo, al momento de escribir este artículo, el destino político de la derecha y de la izquierda es variado e incierto. En abril del 2004, sondeos de opinión pública mostraron que lideres prominente de la Concertación, particularmente la Ministra de Defensa, Michelle Bachelet, y la Ministra de Relaciones Exteriores, Soledad Alvear, podrian ganar a Joaquin Lavin en una competencia mano a mano. No obstante, no se puede predecir si este decaimiento en los sondeos de opinión pública es el signo de un profundo deterioro en el apoyo para Lavín 0 una reacción de corto plazo a los escándalos y las divisiones de la Alianza.

Alternativamente, si Lavín sale adelante, la Concertación dependería exclusivamente de elecciones simultáneas como un potencial incentivo moderadamente unificador en las próximas elecciones. Sin embargo, será una elección simultánea con una expectativa de pérdida presidencial para 
el candidato de la Concertación. Además, una variable no considerada aquí puede socavar los beneficios potenciales que quizás serían cosechados por las elecciones simultáneas. Si la Concertación es incapaz de elegir un candidato presidencial único, los potenciales beneficios proporcionados por las elecciones simultáneas se perderían, y habrían desincentivos adicionales para el mantenimiento de la coalición. Con todo, en el camino a la elección del 2005, si Joaquín Lavín recupera el liderazgo en la carrera presidencial, los incentivos suministrados por el sistema electoral para el mantenimiento de la coalición estarían en su punto más bajo desde el retorno de la democracia, como sugiere la Tabla $4^{10}$. Paralelamente, si Joaquín Lavín cae no sólo de apariencia en las encuestas, muchos de los incentivos que crea el sistema electoral para el fortalecimiento de la coalición gobernante puedan surgir nuevamente.

\section{CONCLUSIONES}

Este artículo no sugiere que tres simples variables determinan los incentivos para el mantenimiento y la estabilidad de las coaliciones en el sistema de partidos chilenos. Existen otras variables políticas que pueden ser mucho más importantes. Por ejemplo, si el Presidente Lagos experimenta una pérdida dramática de apoyo como resultado del decaimiento de la recuperación económica, o del decaimiento en el apoyo hacia la Concertación (un fenómeno ya sugerido por la poca superioridad en votos obtenida por Lagos en las elecciones pasadas), los demócratas cristianos tendrán un fuerte incentivo para ir solos a las elecciones parlamentarias del 2005. Ciertamente, una caída en el apoyo de la izquierda puede, incluso, acentuar el atractivo para presentar candidatos presidenciales separados. Cada partido estará también tentado en presentar una lista parlamentaria separada si cree que solo podría superar los umbrales electorales, o bien si el costo de una alianza con un candidato presidencial de un partido impopular no está asociado a los beneficios potenciales de una alianza electoral en las elecciones legislativas. Paralelamente, muchos habrán advertido el ensanchamiento de la fisura al interior de la Concertación, producto de los asuntos que tradicionalmente dividen a los políticos chilenos a lo largo de sus mayores líneas de clivajes. El conflicto sobre el divorcio, el aborto y la privatización han expuesto las líneas de falla de la Concertación. Finalmente, la coalición está alcanzando un punto de cansancio en términos del decaimiento electoral.

Mientras expertos, practicantes y analistas han notado fisuras ideológicas, desacuerdos y cansancio general en el gobierno de la Concertación como evidencia de una división potencial en la coalición, casi siempre se apunta al sistema electoral como un factor decisivo que puede ayudar a contrarrestar estas fuerzas centrífugas. Sin embargo, este artículo ha demostrado que el sistema electoral en sí mismo también puede ejercer tendencias desintegradoras. La Concertación se formó por la confluencia de una serie de incentivos, incluyendo la relativa igualdad de los subpactos, la concurrencia con elecciones, la probable victoria de presidentes, y la capacidad de hacer promesas post electorales. Estos son elementos que cuando transforman, también cambian la dinámica operacional del sistema electoral.

Las lecciones que provee el caso chileno también proporcionan enseñanzas teóricas ampliamente pertinentes. Las leyes concernientes a los efectos de sistemas electorales a menudo son tratadas como estáticas, universales y mecánicas. Es decir, con frecuencia los analistas tienden a sostener 
que los sistemas electorales causan ciertos efectos sobre el sistema de partidos. Este análisis muestra que los efectos de los sistemas electorales sobre la formación de coaliciones son menos absolutos de lo que parecen a simple vista, subrayando hallazgos recientes que nos fuerzan a repensar en profundidad en la relación entre las reglas electorales y sus supuestos resultados en términos de la dinámica competitiva del sistema de partidos, especialmente fuera de los Estados Unidos y Europa Occidental (Coppedge, 1997; Siavelis, 1997; Weyland, 2002). Con diferentes variables contextuales, las dinámicas operacionales de los sistemas electorales son también distintas.

Expertos han reconocido la relación entre sistemas electorales y el número de partidos y coaliciones, y la competencia dinámica entre ellos. Sin embargo, variaciones mucho más sutiles en las áreas de selección de candidatos, la sincronización y la secuencia de las elecciones, y la capacidad para recompensar a los perdedores (sólo por nombrar unos pocos) pueden afectar profundamente las consecuencias de las distintas fórmulas electorales para los sistemas de partidos.

\section{REFERENCIAS}

Carey, John C. 2002. "Parties, Coalitions, and the Chilean Congress in the 1990's". En Legislative Politics in Latin America, editado por Scott Morgenstern y Benito Nacif. New York: Cambridge University Press.

Carey, John C. 1994. "Los efectos del ciclo electoral sobre el sistema de partidos y el respaldo parlamentario al Ejecutivo". Estudios Públicos 55:305-313.

Carey, John C. y Peter M. Siavelis. 2003. "Seguro para los subcampeones electorales y la sobrevivencia de la Concertación". Estudios Públicos 90:5-27.

Coppedge, Michael. 1997. "District Magnitude, Economic Performance, and Party-System Fragmentation in Five Latin American Countries". Comparative Political Studies 30 (2):156-185.

Cox, Gary. 1997. Making Votes Count. Cambridge, UK: Cambridge University Press.

Dow, Jay. 1998. "A Spatial Analysis of Candidate Competition in Dual Member Districts: The 1989 Chilean Senatorial Elections". Public Choice 97(3):451-74.

Downs, Anthony. 1957. An Economic Theory of Democracy. New York: Harper and Row.

Duverger, Maurice. 1963. Political Parties. New York: John Wiley.

Ensalaco, Mark. 1994. "In with the New Out with the Old?: The Democratising Impact of Constitutional Reform in Chile". Journal of Latin American Studies 26(2):409-429.

Jones, Mark. 1995. Electoral Laws and the Survival of Presidential Democracies. Notre Dame, IN: University of Notre Dame Press. Gutiérrez, Hernán. 1990. "Chile 1989: ¿Elecciones fundacionales?” Documento de trabajo serie Estudios Públicos, No. 3, FLACSO, Santiago (October).

Guzmán, Eugenio. 1993. "Reflexiones sobre el sistema binominal”. Estudios Públicos 51: 303-325.

Lijphart, Arend. 1994. Electoral Systems and Party Systems: A Study of Twenty-Seven Democracies, 1945-1990. Oxford: Oxford University Press.

Linz, Juan J. 1994. “Democracy: Presidential or Parliamentary: Does it Make a Difference?". En The Failure of Presidential Democracy (Vols. 1 y 2), editado por Juan Linz y Arturo Valenzuela. Baltimore: Johns Hopkins University Press.

Magar Eric, Marc Rosenblum y David Samuels 1998. "On the Absence of Centripetal Incentives in Double Member Districts: The Case of Chile". Comparative Political Studies 31(6): 714-39.

Mainwaring, Scott y Matthew Shugart. 1997. Presidentialism and Democracy in Latin America. New York: Cambridge University Press.

Montes, Esteban, Scott Mainwaring y Eugenio Ortega. 2000. "Rethinking the Chilean Party System". Journal of Latin American Studies 32 (3):795-824.

Munck, Gerardo y Jeffrey Bosworth. 1998. "Patterns of Representation and Competition: Parties and Democracy in PostPinochet Chile". Party Politics 4 (4):471-493. 
Rabkin, Rhoda. 1996. "Redemocratization, Electoral Engineering, and Party Strategies in Chile, 1989-1995". Comparative Political Studies 29(3):335-356.

Reed, S.R. 1990. "Structure and Behaviour: Extending Duverger's Law to the Japanese Case". British Journal of Political Science 20 (3):335-56.

Shugart, Matthew. 1995. "The Electoral Cycle and Institutional Sources of Divided Government". American Political Science Review 89 (2):327-343.

Siavelis, Peter. 1997. "Continuity and Change in the Chilean Party System: On the Transformational Effects of Electoral Reform". Comparative Political Studies 30(6):651-674.

Siavelis, Peter. 2002. "The Hidden Logic of Candidate Selection for Chilean Parliamentary Elections". Comparative Politics 34 (4):419-438.

Taagepera, Rein y Matthew Shugart. 1989. Seats and Votes: The Effects and Determinants of Electoral Systems. New Haven, CT: Yale University Press.

Valenzuela, Arturo. 1994. "Party Politics and the Crisis of Presidentialism in Chile". En The Failure of Presidential Democracy (Vols. 1 y 2), editado por Juan Linz y Arturo Valenzuela. Baltimore: Johns Hopkins University Press.

Valenzuela, J. Samuel y Timothy Scully. 1997. "Electoral Choices and the Party System in Chile: Continuities and Changes at the Recovery of Democracy". Comparative Politics 29(4):511-527.

Weyland, Kurt. 2002. "Limitations of Rational-Choice Institutionalism for the Study of Latin American Politics". Studies in Comparative International Development 37(1):57-85.

Peter Siavelis es Profesor asociado de Ciencia Política en Wake Forest University. Es autor de The President and Congress in Post-authoritarian Chile: Institutional Constraints to Democratic Consolidation (Penn State Press, 2000), y de varios capitulos de libros y artículos en revistas profesionales. Su trabajo ha aparecido en Revista de Ciencia Política, Estudios Públicos, Comparative Politics y Comparative Political Studies. Su agenda de investigación actual se centra en el reclutamiento político y la selección de candidatos en América Latina.

(E-Mail: siavelpm@wfu.edu) 